\title{
Experimental and Theoretical Studies of the Corrosion Inhibition of 4-amino-2-(4-chlorophenyl)-8-(2, 3-dimethoxyphenyl)-6-oxo-2, 6-dihydropyrimido $[2,1-b][1,3]$ thiazine-3,7-dicarbonitrile on Carbon Steel in a 1.0 M HCl Solution
}

\author{
H. Serrar ${ }^{a, *}$, M. Larouj ${ }^{b, c}$, H.L. Gaz ${ }^{b, c}$, Z. Benzekri ${ }^{a}$, A. Zarguil ${ }^{a}$, \\ H. Essebaai ${ }^{d}$, S. Boukhris ${ }^{a}$, H. Oudda ${ }^{b}$, R. Salghi ${ }^{c}$, \\ A. Hassikou ${ }^{a}$ and A. Souizi ${ }^{a}$ \\ ${ }^{a}$ Laboratory of Organic, Organometallic and Theoretical Chemistry, Department of Chemistry, \\ Faculty of Sciences, University Ibn Tofail, 14000 Kenitra, Morocco \\ ${ }^{b}$ Laboratory of Separation Processes, Central Post, Department of Chemistry, \\ Faculty of Sciences, University Ibn Tofail, 14000 Kenitra, Morocco \\ ${ }^{c}$ Equipe de Génie de l'Environnement et Biotechnologie, ENSA, \\ Université Ibn Zohr, BP1136 Agadir, Morocco \\ ${ }^{\mathrm{d}}$ Laboratory of Organic Synthesis and Extraction Processes, Department of Chemistry, Faculty \\ of Sciences, University Ibn Tofail, 14000 Kenitra, Morocco
}

Received January 5, 2017; accepted May 25, 2017

\begin{abstract}
The corrosion inhibition of carbon steel in a $1.0 \mathrm{M} \mathrm{HCl}$ solution, using 4-amino-2-(4 chlorophenyl)-8-(2,3-dimethoxyphenyl)-6-oxo-2,6-dihydropyrimido[2,1b][1,3]thiazine3,7-dicarbonitrile (ACMPT) was investigated by weight loss, potentiodynamic polarization, electrochemical impedance spectroscopy (EIS) and quantum chemical calculations. Polarization curves indicate that the studied compound was acting as a mixed inhibitor with predominant cathodic effectiveness. The inhibition efficiency decreased with an increased temperature, and the thermodynamic and activation parameters obtained from this study were discussed. The adsorption behavior of ACMT follows Langmuir's isotherm. In addition, Density Function Theory (DFT) calculations were performed on the studied molecule. The theoretical parameters obtained from this method are in good agreement with the experimental results.
\end{abstract}

Keywords: pyrimidothiazine, carbon steel, corrosion inhibition, theoretical studies, DFT.

\section{Introduction}

Mild steel is widely used in different areas, such as in chemical processing, marine application, petroleum production and refining, and construction [1-4]. Furthermore, hydrochloric acid solutions are widely used for the pickling,

\footnotetext{
* Corresponding author. E-mail address: serrar.doc2015@gmail.com
} 
cleaning, desaling and etching of mild steel [5-7]. In the other hand, hydrochloric acid is the most difficult to handle of the common acids, from the standpoint of corrosion and construction materials. It is required an extreme care to choose the right material to handle this acid by itself, even in relatively dilute concentrations, or in process solutions containing it in appreciable amounts. This acid is well-known for its corrosive capacity towards the most common metals and alloys [8]. One of the most used methods for the protection against corrosion, especially in acidic solutions, is the use of inhibitors [9]. The development of organic inhibitors containing nitrogen, sulphur and oxygen atoms is of growing interest in the field of corrosion and industrial chemistries, as corrosion poses a serious problem to the iron industry $[10,11]$. In the other hand, quantum chemical calculations became widely reputed and used to study reaction mechanisms, and to interpret the experimental results, as well as to resolve chemical ambiguities [12]. The choice of pyrimidothiazine as an inhibitor is based on the good results obtained with this type of heterocyclic compounds in different media [13-16]. In the present work, 4-amino-2-(4-chlorophenyl)-8-(2,3dimethoxyphenyl)-6-oxo-2,6-dihydropyrimido[2,1-b] [1,3] thiazine-3,7dicarbonitrile (ACMPT) was investigated as a corrosion inhibitor for carbon steel in $1.0 \mathrm{M} \mathrm{HCl}$, using detailed gravimetric measurements, electrochemical impedance spectroscopy and quantum chemical calculations. The molecular structure of this pyrimidothiazine derivative is shown in Fig 1.<smiles>COc1cccc(-c2nc3n(c(=O)c2C#N)C(N)=C(C#N)C(c2ccc(Cl)cc2)S3)c1OC</smiles>

Figure 1. Molecular structure of 4-amino-2-(4-chlorophenyl)-8-(2, 3-dimethoxyphenyl)6-oxo-2, 6-dihydropyrimido[2,1-b][1, 3]thiazine-3,7-dicarbonitrile.

\section{Experimental methods}

Materials and methods

Materials

The metal used in this study is carbon steel (CS) (Euronorm: C35E carbon steel and US specification: SAE 1035); Table 1 shows its chemical composition:

Table 1. Chemical composition of carbon steel.

\begin{tabular}{|c|c|c|c|c|c|c|c|c|c|c|}
\cline { 2 - 10 } \multicolumn{1}{c|}{} & $\mathbf{C}$ & $\mathbf{S i}$ & $\mathbf{M n}$ & $\mathbf{S}$ & $\mathbf{C r}$ & $\mathbf{T i}$ & $\mathbf{N i}$ & $\mathbf{C o}$ & $\mathbf{C u}$ & $\mathbf{F e}$ \\
\hline wt\% & 0.370 & 0.230 & 0.680 & 0.016 & 0.077 & 0.011 & 0.059 & 0.009 & 0.160 & remainder iron \\
\hline
\end{tabular}

Synthesis

Pyrimidin-4-one (1 mmol) was added to a solution of 2-(2, 3-dimethoxybenzylidene) malononitrile $(1 \mathrm{mmol})$ in acetonitrile $(20 \mathrm{~mL})$. The mixture was then 
refluxed for $30 \mathrm{~h}$. The solvent was removed under reduced pressure, and the crude product was treated with a mixture of ether/petroleum ether and the 4amino-2-(4-chlorophenyl)-8-(2,3-dimethoxyphenyl)-6-oxo-2,6-

dihydropyrimido[2,1-b][1,3]thiazine-3,7-dicarbonitrile (ACMPT) precipitate, and it was recrystallized from EtOH. The synthetic approaches adopted to obtain the target compounds (ACMOPT) are shown in Scheme 1.

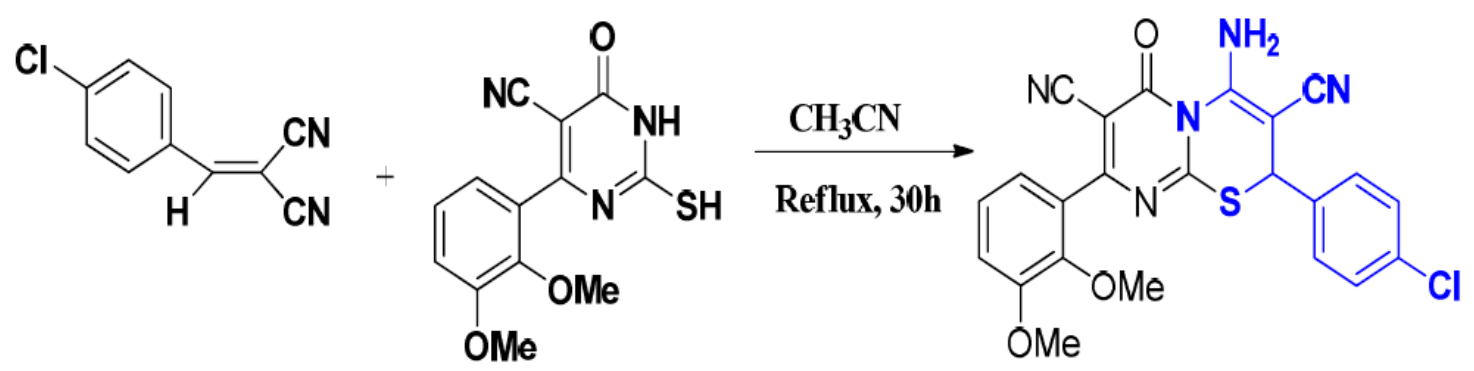

Scheme 1. Synthesis of 4-amino-2-(4-chlorophenyl)-8-(2,3-dimethoxyphenyl)-6-oxo-2,6dihydropyrimido[2,1-b] [1,3]thiazine-3,7-dicarbonitrile (ACMPT).

\section{Solution}

The aggressive solution of $1.0 \mathrm{M} \mathrm{HCl}$ was prepared by the dilution of analytical grade $37 \% \mathrm{HCl}$ with distilled water. The concentration range of used 4-amino-2(4-chlorophenyl)-8-(2, 3-dimethoxyphenyl)-6-oxo-2, 6-dihydropyrimido[2, 1b][1,3] thiazine-3,7-dicarbonitrile (ACMPT) was $10^{-6}$ to $10^{-3} \mathrm{M}$.

\section{Weight loss measurements}

Gravimetric measurements were carried out at a definite time interval of $4 \mathrm{~h}$, at room temperature, using an analytical balance (precision $\pm 0.1 \mathrm{mg}$ ). The used carbon steel specimens had a rectangular form (length $=1.6 \mathrm{~cm}$, width $=1.6 \mathrm{~cm}$, thickness $=0.07 \mathrm{~cm}$ ). Gravimetric experiments were carried out in a double glass cell equipped with a thermostated cooling condenser containing $80 \mathrm{~mL}$ of the non-de-aerated test solution. After the immersion period, the steel specimens were withdrawn, carefully rinsed with bidistilled water, ultrasonic cleaned in acetone, dried at room temperature and then weighed. Triplicate experiments were performed in each case, and the mean value of the weight loss was calculated.

\section{Electrochemical measurements}

\section{Electrochemical impedance spectroscopy}

The electrochemical measurements were carried out with a Voltalab (TacusselRadiometer PGZ 100) potentiostat, and controlled by Tacussel corrosion analysis software model (Voltamaster 4) under static conditions. The used corrosion cell had three electrodes. The reference electrode was a saturated calomel electrode (SCE). A platinum electrode was used as auxiliary electrode, with a surface area of $1 \mathrm{~cm}^{2}$. The working electrode was carbon steel.

All potentials given in this study were referred to this reference electrode. The working electrode was immersed in a test solution for $30 \mathrm{~min}$, to establish a 
steady state open circuit potential (Eocp). After measuring the Eocp, the electrochemical measurements were performed. All electrochemical tests have been performed in aerated solutions at $303 \mathrm{~K}$. The ESI experiments were conducted in the frequency range with a high limit of $100 \mathrm{KHz}$, and a different low limit of $0.1 \mathrm{~Hz}$ at open circuit potential, with 10 points per decade, at the rest potential after $30 \mathrm{~min}$ of immersion in the acid, by applying $10 \mathrm{mV}$ ac voltage peak-to-peak. Nyquist plots were made from these experiments. The best semicircle could be fit through the data points in the Nyquist plot, using a nonlinear least square fit, so as to give the intersections with the X-axis.

The inhibition efficiency was calculated from the charge transfer resistance values using the following equation [17]:

$$
\eta_{z} \%=\frac{R_{c t}^{i}-R_{c t}^{o}}{R_{c t}^{i}} \times 100
$$

where $\mathrm{R}_{c t}^{\circ}$ and $\mathrm{R}_{\mathrm{ct}}^{\mathrm{i}}$ are the charge transfer resistance, respectively in the absence and presence of inhibitor.

\section{Potentiodynamic polarization}

The electrochemical behavior of a carbon steel sample in inhibited and uninhibited solutions was studied by recording anodic and cathodic potentiodynamic curves. Measurements were performed in the $1.0 \mathrm{M} \mathrm{HCl}$ solution containing different concentrations of the tested inhibitor, by automatically changing the electrode potential from 800 to $-100 \mathrm{mV}$ versus the corrosion potential at a scan rate of $2 \mathrm{mV} . \mathrm{s}^{-1}$. The linear Tafel segments of anodic and cathodic curves were extrapolated to the corrosion potential to obtain corrosion current densities ( $\left.\mathrm{I}_{\text {corr }}\right)$. From the obtained polarization curves, the corrosion current $\left(\mathrm{I}_{\text {corr }}\right)$ was calculated by the curve fitting using the following equation:

$$
I=I_{\mathrm{corr}}\left[\exp \left(\frac{2.3 \Delta E}{\beta \mathrm{a}}\right)-\exp \left(\frac{2.3 \Delta E}{\beta \mathrm{c}}\right)\right]
$$

The inhibition efficiency was evaluated from the measured $I_{\text {corr }}$ values usm the following relationship [18]:

$$
\eta_{\text {Tafel }} \%=\frac{I_{\text {corr }}^{o}-I_{c o r r}^{i}}{I_{\text {corr }}^{o}} \times 100
$$

where $\mathrm{I}^{\circ}$ corr and $\mathrm{I}_{\text {corr }}^{\mathrm{i}}$ are the corrosion current density, respectively in the absence and presence of the inhibitor. 


\section{Computational details}

Density Functional Theory (DFT) has been recently used [18-22] to describe the interaction between the inhibitor molecule and the surface, as well as the properties of these inhibitors concerning their reactivity. The molecular hand gap was computed as the first vertical electronic excitation energy from the ground state using the time dependent density functional theory (TD-DFT) approach, as implemented in Gaussian 03 [23]. For this purpose, some molecular descriptors, such as HOMO and LUMO energy values, frontier orbital energy gap, molecular dipole moment electronegativity $(\chi)$, global hardness $(\eta)$, softness $(S)$ and the fraction of transferred electrons $(\Delta \mathrm{N})$ were calculated using DFT method, and have been used to understand the inhibitors' properties, to help in the explanation of the experimental data obtained for the corrosion process.

According to Koopman's theorem [24], the ionization potential (IE) and electron affinity (EA) of the inhibitors are calculated using the following equations:

$$
\begin{aligned}
& \mathrm{IE}=-\mathrm{E}_{\text {HOMO }} \\
& \mathrm{EA}=-\mathrm{E}_{\text {LUMO }}
\end{aligned}
$$

Thus, the values of electronegativity $(\chi)$ and chemical hardness $(\eta)$ that, according to Pearson, are operational and approximate definitions, can be evaluated using the following relation [25]:

$$
\begin{aligned}
& \chi=(\mathrm{IE}+\mathrm{EA}) / 2 \\
& \eta=(\mathrm{IE}-\mathrm{EA}) / 2
\end{aligned}
$$

The number of transferred electrons $(\Delta N)$ was also calculated depending on the quantum chemical method [26, 27].

$$
\eta=\frac{\chi_{F e}-\chi_{i n h}}{2\left(\eta_{F e}+\eta_{i n h}\right)}
$$

where $\chi_{\mathrm{Fe}}$ and $\chi_{\text {inh }}$ donate the absolute electronegativity of iron and of the inhibitor molecule, and $\eta_{\mathrm{Fe}}$ and $\eta_{\text {inhi }}$ donate the absolute hardness of iron and of the inhibitor molecule. In this study, we use the theoretical values of $\chi_{\mathrm{Fe}}$ for the absolute hardness of iron and of the inhibitor molecule, and we use the theoretical value of $\chi_{\mathrm{Fe}}=7.0 \mathrm{eV}$ and $\eta_{\mathrm{Fe}}=0$ to calculate the number of transferred electrons.

\section{Results and discussion \\ Polarization curves}

In the present paper, a potentiodynamic polarization study has been made in order to understand the role of the inhibitor in biasing anodic and cathodic reactions. Fig. 2 shows the anodic and cathodic polarization plots of carbon steel in a $1.0 \mathrm{M} \mathrm{HCl}$ solution, in the absence and presence of different concentrations of the ACMPT inhibitor at $298 \mathrm{~K}$, while Table 2 shows electrochemical 
corrosion parameters, such as corrosion potential ( $\left.\mathrm{E}_{\mathrm{corr}}\right)$, corrosion current density ( $\left.\mathrm{I}_{\text {corr }}\right)$ and inhibition efficiency $(\eta \mathrm{IE} \%)$.

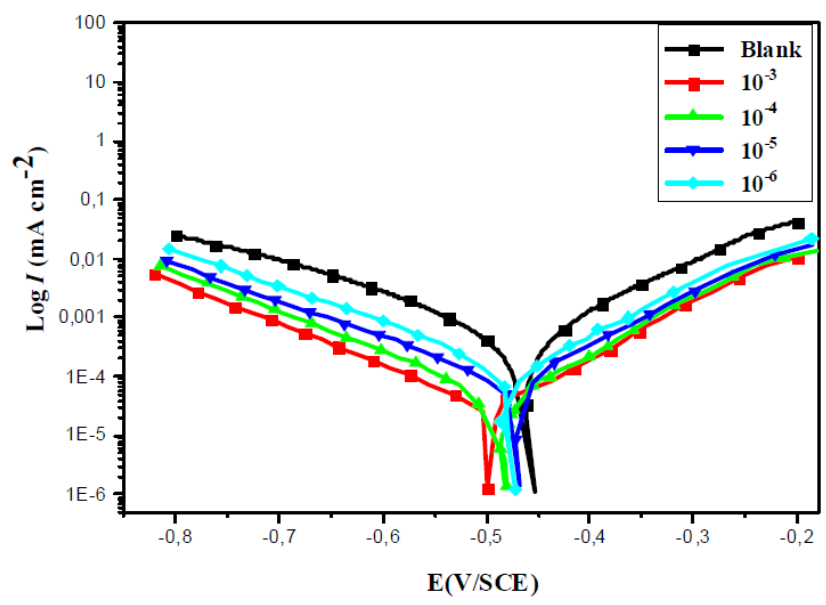

Figure 2. Potentiodynamic polarization curves of carbon steel in $1.0 \mathrm{M} \mathrm{HCl}$, in the presence of different concentrations of ACMPT.

It is noted from Fig. 2 that the polarization curves in the $1.0 \mathrm{M} \mathrm{HCl}$ solution, containing different concentrations of the studied pyrimidothiazine, are nearly the same. In addition, cathodic and anodic current densities of the polarization curves are both reduced [28, 29].

The above results indicate that retardation of the samples corrosion processes at cathodic and anodic reaction sites occurred, and this was due to the adsorption of these sites by the inhibitor molecules [30-33].

Table 2. Electrochemical parameters of carbon steel at various concentrations of ACMPT in $1.0 \mathrm{M} \mathrm{HCl}$, and corresponding inhibition efficiency.

\begin{tabular}{cccccc}
\hline Inhibitor & $\begin{array}{c}\text { Conc } \\
(\mathbf{M})\end{array}$ & $\begin{array}{c}-\mathbf{E}_{\mathbf{c o r r}} \\
(\mathbf{m V} / \mathbf{S C E})\end{array}$ & $\begin{array}{c}\mathbf{I}_{\text {corr }} \\
\left(\boldsymbol{\mu} \mathbf{A} \mathbf{~ c m}^{-2}\right)\end{array}$ & $\begin{array}{c}-\boldsymbol{\beta}_{\mathbf{c}} \\
\left(\mathbf{m V} \mathbf{d e c}^{-1}\right)\end{array}$ & $\begin{array}{c}\boldsymbol{\eta}_{\text {Tafel }} \\
(\boldsymbol{\%})\end{array}$ \\
\hline Blank & 1.0 & 469 & 588 & 168 & - \\
\hline & $1 \times 10^{-3}$ & 499 & 44.98 & 140 & 92.35 \\
\cline { 2 - 6 } & $1 \times 10^{-4}$ & 481 & 50.03 & 156 & 91.49 \\
\cline { 2 - 6 } ACMPT & $1 \times 10^{-5}$ & 470 & 61.03 & 173 & 89.62 \\
\cline { 2 - 6 } & $1 \times 10^{-6}$ & 474 & 89.26 & 157 & 84.82 \\
\hline
\end{tabular}

On the other hand, cathodic Tafel curves gave rise to parallel Tafel lines, indicating that hydrogen evolution reaction is activation-controlled, that a stronger inhibition effect of the inhibitors does not affect the reduction mechanism, and that their inhibition action is blocking the metal surface [34].

Based on Fig. 2 and Table 2, it is obvious that the value of $\beta_{c}$ changed with the increase in the inhibitor's concentration, indicating the influence of the inhibitor on the kinetics of the hydrogen evolution [35].

In addition to what was previously described, an inhibitor can generally be classified as from the cathodic or anodic type, if the shift of corrosion potential in the presence of the inhibitor is more than $85 \mathrm{mV}$, with respect to the corrosion potential of the blank solution. 
In the present study, the maximum displacement was $30 \mathrm{mV}$, suggesting that ACMPT can be arranged as a mixed type inhibitor, with predominant cathodic effectiveness [36, 37].

Also, the examination of Table 2 concludes that the corrosion current density $\left(\mathrm{I}_{\text {corr }}\right)$ values of carbon steel, in the presence of the ACMPT inhibitor, are lower than those found without inhibitor.

It is noted that the inhibitory efficiency (IE\%) increased with the increase in the inhibitor's concentration, and reached a maximum value of $92.35 \%$ for a concentration of $10^{-3} \mathrm{M}$ of the studied inhibitor.

\section{Electrochemical impedance spectroscopy measurements}

The corrosion behavior of carbon steel in $1.0 \mathrm{M} \mathrm{HCl}$, in the absence and presence of various concentrations of ACMPT, was also investigated by EIS technique. The resultant Nyquist plots are shown in Fig. 3.

The values of inhibition efficiency $\left(\left(\eta_{\mathrm{z}} \%\right)\right.$ were calculated by the equation (1).

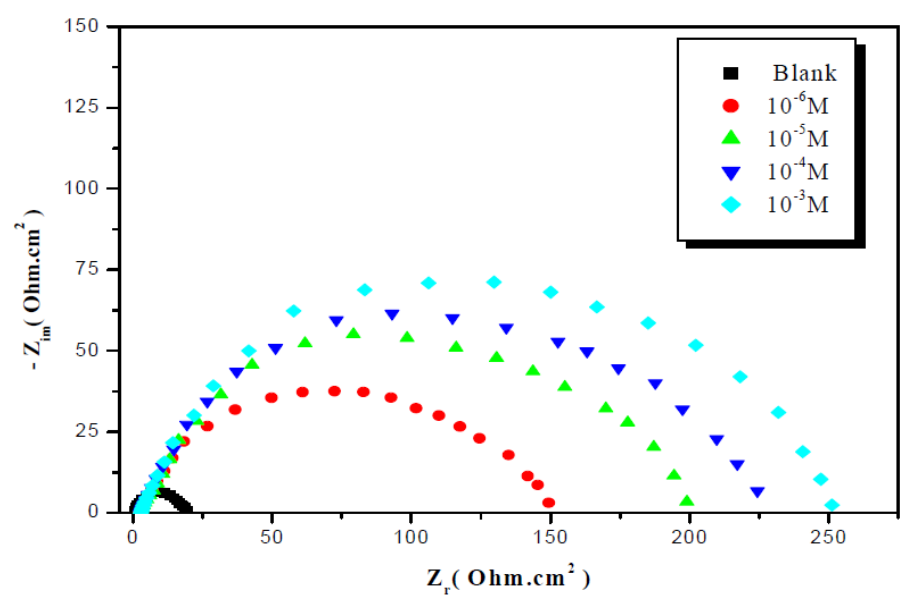

Figure 3. Nyquist diagrams for a carbon steel electrode with and without ACMPT at $298 \mathrm{~K}$, after $30 \mathrm{~min}$ of immersion.

To obtain the values of double layer capacitance $\left(\mathrm{C}_{\mathrm{dl}}\right)$, the values of frequency at which the imaginary component of the impedance is maximum $-\mathrm{Z}_{\mathrm{im}(\max )}$ were found and used in the following equation with corresponding $\mathrm{R}_{\mathrm{ct}}$ values:

$$
C_{\mathrm{dl}=} \frac{1}{2 \pi f_{\max } R_{\mathrm{ct}}}
$$

Nyquist plots contain a semicircle with the center under real axis. The size of the semicircle increases with the inhibitor's concentration, indicating the charge transfer process as the main controlling factor for the corrosion inhibition of carbon steel. As we could see from the plots, the impedance of the inhibited solution has increased with the increase in the inhibitor's concentration.

The experimental results of EIS measurements for the corrosion of carbon steel in $1.0 \mathrm{M} \mathrm{HCl}$, in the absence and presence of inhibitor, are given in Table 3.

As it can be observed from Table 3 , the charge transfer resistance $\left(R_{c t}\right)$ value increased with the increase in the inhibitor's concentration. Inversely, values of the interface's capacitance $\left(\mathrm{C}_{\mathrm{dl}}\right)$ started decreasing, with the increase in the inhibitor's concentration, which is most probably due to the decrease in local 
dielectric constant and/or to the increase in thickness of the electrical double layer. This suggests that the inhibitor acts via adsorption at the metal/solution interface [38], and that the decrease in the $C_{d l}$ values is caused by the gradual replacement of water molecules by the adsorption of the inhibitor molecules onto the electrode surface, which decreases the extent of metal dissolution [39]. A keen observation of these plots has revealed that capacitive loops are not perfect semicircles, which is possibly due to the frequency dispersion, roughness, and inhomogeneity of the metal surface, and to impurities, grain boundaries, and distribution of the surface's active sites. The existence of a single semicircle can be attributed to the single charge transfer reaction during the metal dissolution process [40].

Table 3. Electrochemical impedance parameters for carbon steel corrosion in an acid medium, at various contents of ACMPT.

\begin{tabular}{llclccc}
\hline Inhibitor & $\mathbf{C}(\mathbf{m o l} / \mathbf{L})$ & $\mathbf{R}_{\mathbf{c t}}\left(\mathbf{\Omega . c m}^{2}\right)$ & $\mathbf{f}(\mathbf{m a x})$ & $\mathbf{C}_{\mathbf{d l}}\left(\boldsymbol{\mu} \mathbf{F} / \mathbf{c m}^{2}\right)$ & $\mathbf{E R t}(\boldsymbol{\%})$ & $\boldsymbol{\theta}$ \\
\hline Blank & 1.0 & 21 & 34.31064 & 221 & - & \\
\hline \multirow{4}{*}{ ACMPT } & $1 \times 10^{-3}$ & 250 & 15.83253 & 40.23 & 91.6 & 0.92 \\
\cline { 2 - 7 } & $1 \times 10^{-4}$ & 225 & 16.67564 & 42.44 & 90.7 & 0.91 \\
\cline { 2 - 7 } & $1 \times 10^{-5}$ & 200 & 17.8116 & 44.7 & 89.5 & 0.89 \\
\cline { 2 - 7 } & $1 \times 10^{-6}$ & 150 & 21.10899 & 50.29 & 86.0 & 0.86 \\
\hline
\end{tabular}

The equivalent circuit that describes the present metal/electrolyte corroding system is the simple Randles model shown in Fig. 4, where $R_{s}, R_{c t}$ and $C_{d l}$ are, respectively, the resistance in solution, the charge transfer resistor and the double layer capacitance of the interface.

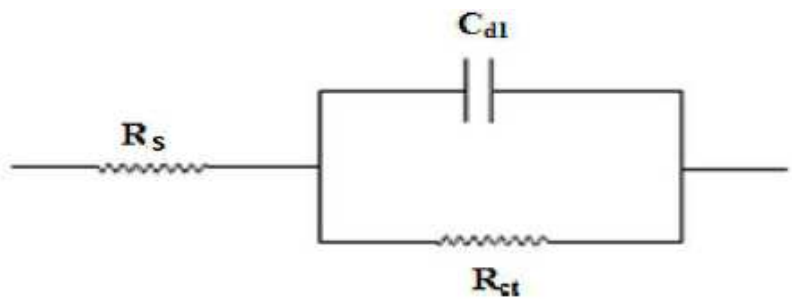

Figure 4. The electrochemical equivalent circuit used to fit the impedance spectra.

\section{Weight loss, corrosion rates and inhibition efficiency}

Fig. 5 indicates the variation of ACMPT's corrosion rate as a function of its concentration in $1.0 \mathrm{M} \mathrm{HCl}$ at $298 \mathrm{~K}$, from weight loss measurements. This figure reveals that the rate of mild steel corrosion in $1.0 \mathrm{M} \mathrm{HCl}$ decreases with an increase in the inhibitor's concentration at $298 \mathrm{~K}$.

The increase in inhibition efficiency with an increase in the concentration of the studied compound can be explained by the increased adsorption of ACMPT on the metal surface (Table 4).

In the inhibition process, the first step in the inhibition mechanism is the adsorption at the metal/aggressive solution interface [41]. Given the dependence of inhibition efficiency on the concentration, as represented in Fig. 6, the inhibitor decreases the active center for steel dissolution. The adsorption process 
is made possible by the presence of heteroatoms such as $\mathrm{N}, \mathrm{S}$ and $\mathrm{O}$, which are regarded as active adsorption centers.

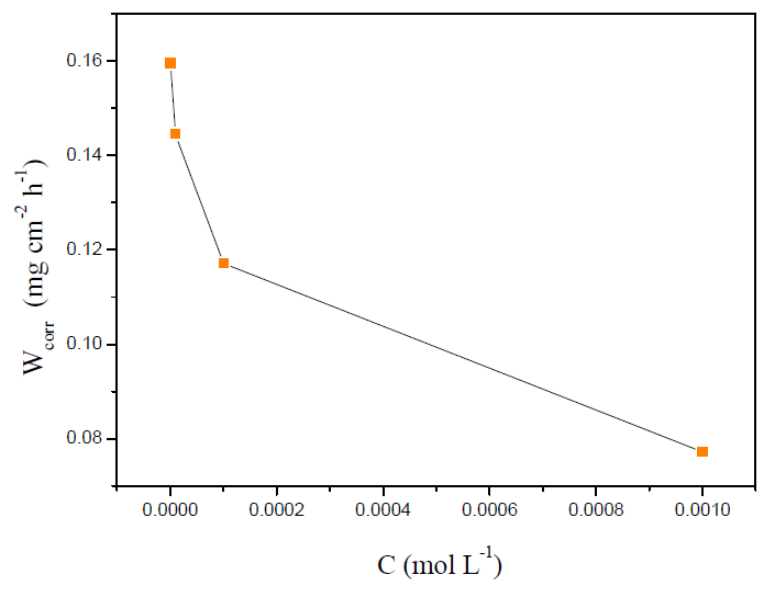

Figure 5. Relationship between the corrosion rate and the inhibitor's concentration for carbon steel, after $4 \mathrm{~h}$ immersion in $1.0 \mathrm{M} \mathrm{HCl}$ at $298 \mathrm{~K}$.

Table 4. Effect of ACMPT's concentration on the corrosion data of carbon steel in $1.0 \mathrm{M}$ $\mathrm{HCl}$.

\begin{tabular}{ccccc}
\hline Inhibitor & concentrations $\mathbf{M}$ & $\mathbf{W}_{\text {corr }}\left(\mathbf{m g ~ c m}^{-2} \mathbf{h}^{-\mathbf{1}}\right)$ & $\mathbf{E}_{\mathbf{w}}(\boldsymbol{\%})$ & $\boldsymbol{\Theta}$ \\
\hline Blank & 1.0 & 1.2043 & ----- & ----- \\
\hline & $1 \times 10^{-3}$ & 0.0772 & 91.59 & 0.9359 \\
ACMPT & $1 \times 10^{-4}$ & 0.1171 & 90.28 & 0.9028 \\
& $1 \times 10^{-5}$ & 0.1445 & 87.00 & 0.8800 \\
& $1 \times 10^{-6}$ & 0.1595 & 85.76 & 0.8676 \\
\hline
\end{tabular}

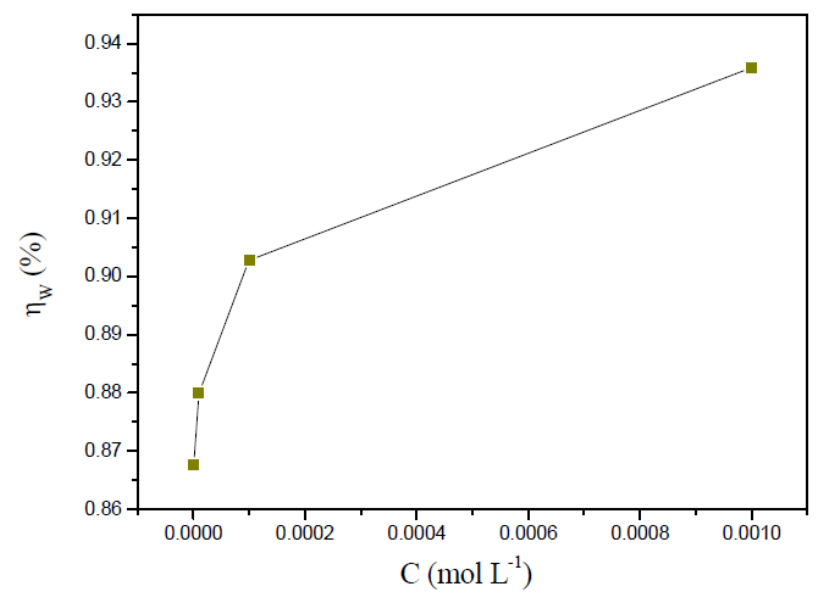

Figure 6. Corrosion inhibition efficiency of ACMPT for carbon steel in $1.0 \mathrm{M} \mathrm{HCl}$, as a function of the concentration at $298 \mathrm{~K}$.

The adsorption of ACMPT on the surface of mild steel can be achieved by the interaction between the pair of single electrons of the heteroatoms or between the electron-rich $\pi$ electron systems and the metal surface. This, as earlier reported by Umoren and Ebenso [42], may be facilitated by the presence of the vacant $d$ orbital of iron that constitutes steel, as observed in $\mathrm{d}$ group metals or in the transition element. In addition to the molecular form, ACMPT can be present in 
protonated species in an acidic solution. This protonated form facilitates the adsorption of the compound onto the metal surface by electrostatic interaction between the organic molecules and the metal surface [43].

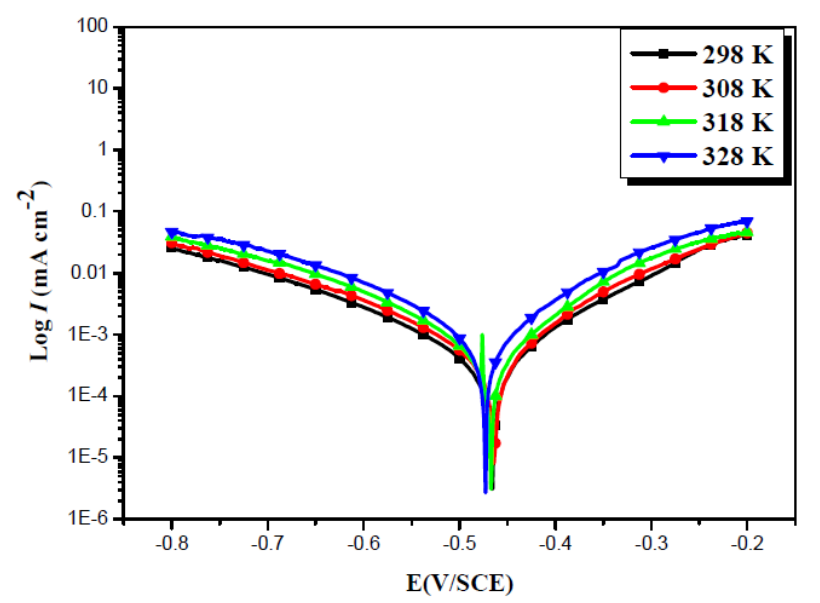

Figure 7. Potentiodynamic polarization curves of carbon steel in $1.0 \mathrm{M} \mathrm{HCl}$ at different temperatures.

\section{Effect of temperature}

The influence of temperature is also studied by potentiodynamic polarization. We have carried out a study in the range of 298-328 K, using stationary electrochemical measurements in potentiostatic mode.

Figs. 7 and 8 show the polarization curves of steel in a $1.0 \mathrm{M} \mathrm{HCl}$ medium, respectively in the absence and presence of $10^{-3} \mathrm{M}$ of ACMPT, in the studied temperature range.

The results deduced from the polarization curves are given in Table 5. As it can be seen, raising the temperature increases both anodic and cathodic reactions of the carbon steel electrode, both in the absence and presence of the organic compound.

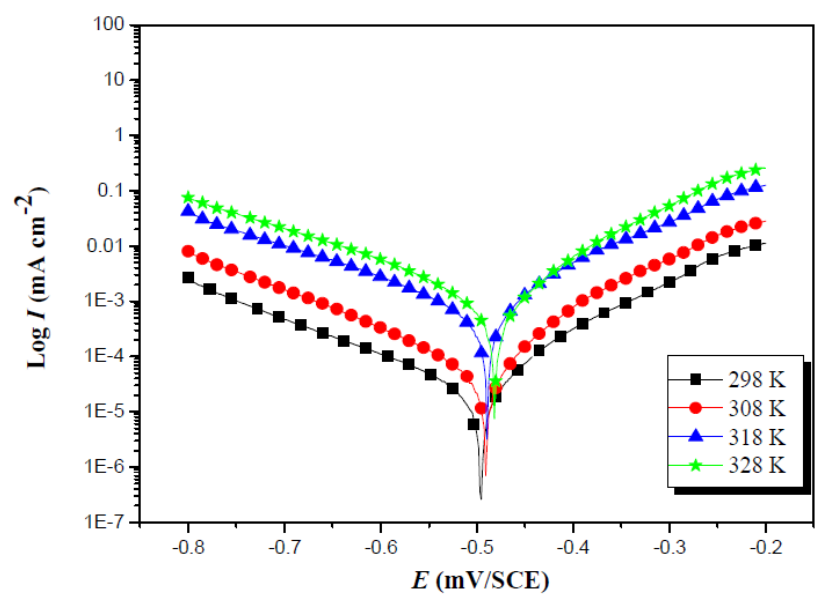

Figure 8. Potentiodynamic polarization curves of carbon steel in $1.0 \mathrm{M} \mathrm{HCl}$, in the presence of $10^{-3} \mathrm{M}$ of the inhibitor at different temperatures. 
Table 5 also shows that the corrosion current density ( $\left.\mathrm{I}_{\text {corr }}\right)$ increased with an increasing temperature, while the investigated pyrimidothiazine derivative kept his inhibiting properties at all studied temperatures.

Table 5. Effect of temperature on carbon steel in free acid and at $10^{-3} \mathrm{M}$ of ACMPT.

\begin{tabular}{|c|c|c|c|c|c|}
\hline Inhibitor & $\begin{array}{c}\text { Conc. } \\
\text { (M) }\end{array}$ & $\begin{array}{c}-\mathbf{E}_{\text {corr }} \\
(\mathrm{mV} / \mathrm{SCE})\end{array}$ & $\begin{array}{c}I_{\text {corr }} \\
\left(\mu \mathrm{A} \mathrm{cm}^{-2}\right)\end{array}$ & $\begin{array}{c}-\beta_{\mathrm{c}} \\
\left(\mathrm{mV} \operatorname{dec}^{-1}\right)\end{array}$ & $\begin{array}{c}\eta_{\text {Tafel }} \\
(\%)\end{array}$ \\
\hline \multirow{4}{*}{ Blank } & 298 & 469 & 588 & 168 & - \\
\hline & 308 & 467 & 896 & 165 & - \\
\hline & 318 & 470 & 3428 & 137 & - \\
\hline & 328 & 477 & 6720 & 125 & - \\
\hline \multirow{4}{*}{ ACMPT } & 298 & 499 & 45 & 159 & 92.35 \\
\hline & 308 & 492 & 96 & 151 & 89.28 \\
\hline & 318 & 490 & 435 & 177 & 87.31 \\
\hline & 328 & 483 & 875 & 167 & 86.98 \\
\hline
\end{tabular}

The inhibition efficiency of ACMPT reaches the maximum values (92.35\%) at $298 \mathrm{~K}$, upon an increased temperature; $\eta \mathrm{IE} \%$ is slightly decreased, and the pyrimidothiazine derivative becomes less effective at $328 \mathrm{~K}$. This behavior again shows the physical nature of ACMPT's adsorption in a $\mathrm{HCl}$ solution.

The activation energy, Ea, was calculated from an Arrhenius-type plot (Eq. 10) $[44,45]$.

$$
I_{\text {corr }}=\operatorname{kexp}\left(\frac{-E_{\mathrm{a}}}{R T}\right)
$$

where $\mathrm{E}$ is the apparent activation corrosion energy, $\mathrm{T}$ is the absolute temperature, $\mathrm{k}$ is the Arrhenius pre-exponential constant and $\mathrm{R}$ is the universal gas constant.

The enthalpy of activation, $\Delta \mathrm{H}_{\mathrm{a}}$, and the entropy of activation, $\Delta \mathrm{Sa}$, were calculated from equation 11 .

$$
I_{\text {corr }}=\frac{R T}{N h} \exp \left(\frac{\Delta S_{\mathrm{a}}}{R}\right) \exp \left(\frac{\Delta \mathrm{H}_{\mathrm{a}}}{R T}\right)
$$

where $\mathrm{h}, \mathrm{N}, \Delta \mathrm{S}_{\mathrm{a}}$ and $\Delta \mathrm{H}_{\mathrm{a}}$ are, respectively, the Planck constant, the Avogadro number, the activation entropy and the activation entropy.

Plots of $\ln \left(\mathrm{I}_{\text {corr }}\right)$ vs. 1000/T and $\ln \left(\mathrm{I}_{\text {corr }} / \mathrm{T}\right)$ vs. 1000/T gave straight lines, respectively with slopes of $-\mathrm{E}_{\mathrm{a}} / \mathrm{R}$ and $-\Delta \mathrm{H}_{\mathrm{a}} / \mathrm{R}$. The intercepts were $\mathrm{A}$ and [ln $\left.(\mathrm{R} / \mathrm{Nh})+\left(\Delta \mathrm{S}_{\mathrm{a}} / \mathrm{R}\right)\right]$, respectively for the Arrhenius and transition state equations.

Figs. 9 and 10 represent the data plots of $\mathrm{Ln}\left(\mathrm{I}_{\text {corr }}\right)$ vs. 1000/T and $\mathrm{Ln}\left(\mathrm{I}_{\text {corr }} / \mathrm{T}\right)$ vs. $1000 / \mathrm{T}$, in the absence and presence of $10^{-3} \mathrm{M}$ ACMPT, as a representative example.

The calculated values from both methods of the activation energy, $E_{a}$, the enthalpy of activation, $\Delta \mathrm{H}_{\mathrm{a}}$, and the entropy of activation, $\Delta \mathrm{S}_{\mathrm{a}}$, are shown in Table 6. From this table, it could be clearly seen that the values of $E_{a}$ and of $\Delta H_{a}$, obtained in the presence of ACMPT, are higher than those obtained in the solution without inhibitor. The positive sign of $\Delta \mathrm{H}_{\mathrm{a}}$ reflects the endothermic 
nature of carbon steel dissolution process, suggesting that the dissolution of carbon steel is slower in the inhibitor's presence [46]. It is also clear that $\mathrm{E}_{\mathrm{a}}$, in the presence of $10^{-3} \mathrm{M}$ of ACMPT, is higher than that obtained in the blank. This observation has been reported to be indicative of physical adsorption mechanism, while lower values of $E_{a}$ suggest a chemisorption mechanism [47, 48].

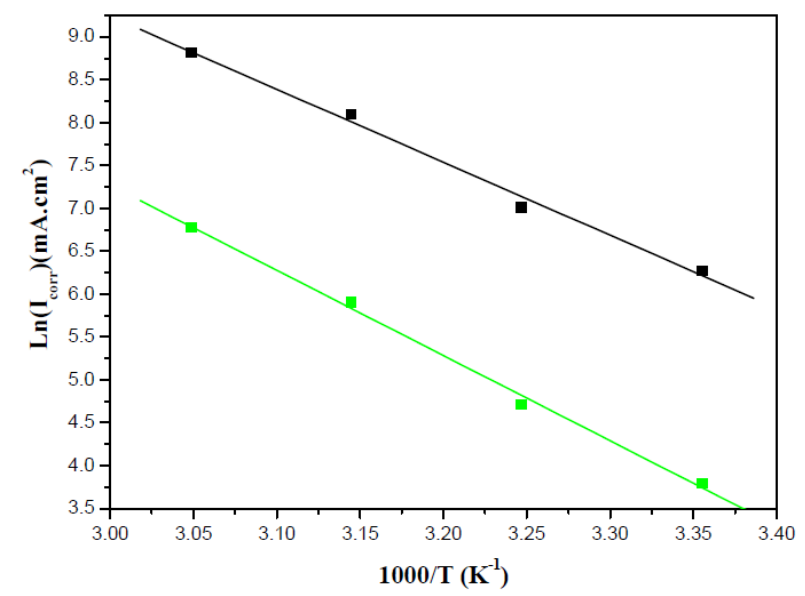

Figure 9. Arrhenius plots of steel in $1.0 \mathrm{M} \mathrm{HCl}$, with and without inhibitor.

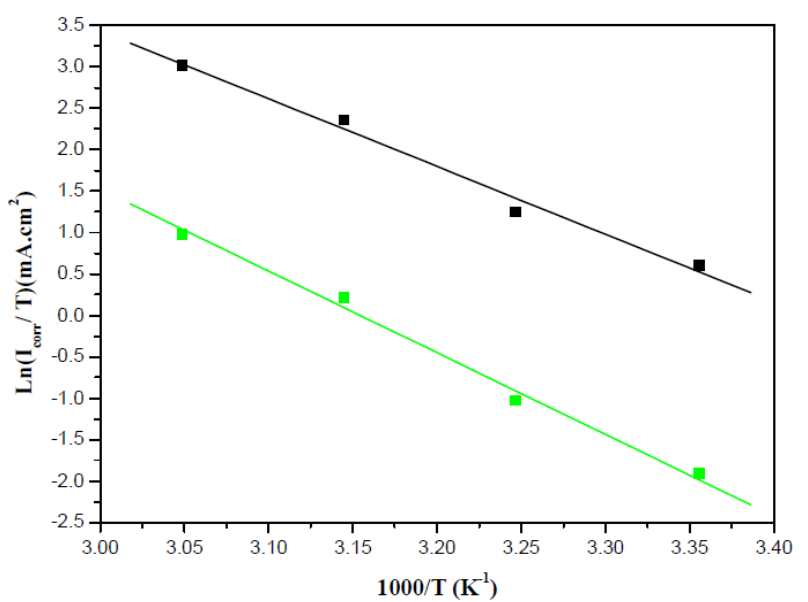

Figure 10. Relation between $\ln \left(\mathrm{I}_{\mathrm{corr}} / \mathrm{T}\right)$ and $1000 / \mathrm{T}$ at different temperatures.

Table 6. Values of activation parameters, $\Delta \mathrm{H}_{\mathrm{a}}, \Delta \mathrm{S}_{\mathrm{a}}$ and $\mathrm{E}_{\mathrm{a}}$, for mild steel in $1.0 \mathrm{M} \mathrm{HCl}$, in the absence and presence of $10^{-3} \mathrm{M}$ of ACMPT.

\begin{tabular}{|c|c|c|c|}
\hline Inhibitor & $\mathbf{E}_{\mathbf{a}}(\mathbf{k J} / \mathbf{m o l e})$ & $\mathbf{\Delta H}_{\mathbf{a}}(\mathbf{k J} / \mathbf{m o l e})$ & $\Delta \mathbf{S}_{\mathbf{a}}(\mathbf{J} / \mathbf{m o l e})$ \\
\hline $\mathbf{1 . 0} \mathbf{M ~ H C l}$ & 70.75 & 68.16 & 33.29 \\
\hline ACMPT & 82.56 & 79.97 & 34.24 \\
\hline
\end{tabular}

The presence of the test compound results in an increase in the $\Delta S_{a}$ values. This result indicates that corrosion changes from a more ordered system into a disordered system, with the increase in the inhibitory nature of the studied compounds [49]. In the presence of the inhibitor, the value of $\Delta S_{a}$ increases, which is generally interpreted as an increase in disorder, as the reactants are converted to the activated complexes [50]. 


\section{Adsorption isotherm and standard adsorption of free energy}

The adsorption isotherm that describes the adsorptive behavior of organic inhibitors is important, in order to know the mechanism of corrosion inhibition. Basic information on the interaction between the inhibitor molecules and the metal surface can be provided by adsorption isotherms. Several adsorption isotherms were attempted to fit the degree of surface coverage values $(\theta)$, including Frumkin, Temkin, Freundlich and Langmuir isotherms. The $\theta$ values for various concentrations of inhibitors in acidic media have been evaluated from the polarization measurements. The best fit was obtained in the case of Langmuir isotherm, which assumes that the solid surface contains a fixed number of adsorption sites, and that each site holds one adsorbed species [51]. The plot of $\mathrm{C}_{\text {inh }} / \theta$ vs. $\mathrm{C}_{\text {inh }}$ (Fig. 11) yields a straight line with a correlation coefficient of 0.99998, providing that the adsorption of ACMPT from the $1.0 \mathrm{M} \mathrm{HCl}$ solution on the carbon steel surface obeys Langmuir adsorption isotherm. This isotherm can be represented as:

$$
\frac{C_{i n h}}{\theta}=\frac{1}{K_{a d s}}+C_{i n h}
$$

where $\mathrm{C}_{\mathrm{inh}}$ is the molar concentration of the inhibitor and $\mathrm{K}_{\mathrm{ads}}$ is the equilibrium constant or the adsorption-desorption process.

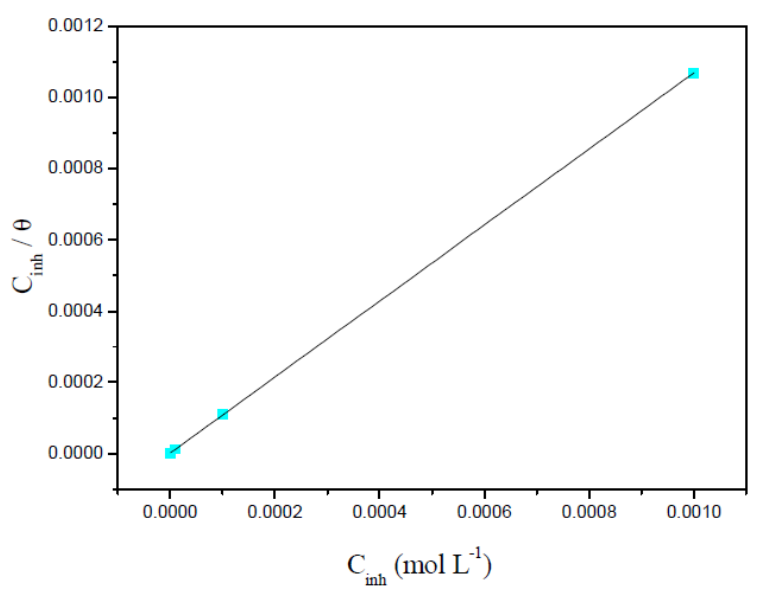

Figure 11. Langmuir adsorption of ACMPT on the carbon steel surface in a $1.0 \mathrm{M} \mathrm{HCl}$ solution.

The value of $\mathrm{K}_{\mathrm{ads}}$ was found to be $654900.3 \mathrm{M}^{-1}$ (Table 7). The relatively high value of the adsorption equilibrium constant reflects the high adsorption ability of ACMPT on the carbon steel surface [52].

Table 7. Thermodynamic parameters for the adsorption of ACMPT in $1.0 \mathrm{M} \mathrm{HCl}$ on carbon steel at $298 \mathrm{~K}$.

\begin{tabular}{|c|c|c|c|c|}
\hline Inhibitor & Slope & $K_{\text {ads }}\left(M^{-1}\right)$ & $R^{2}$ Corr. Coeff. & $\Delta G_{\text {ads }}^{0}(\mathrm{~kJ} / \mathrm{mol})$ \\
\hline ACMPT & 1.06 & 654900.3 & 0.99998 & -43.13 \\
\hline
\end{tabular}


$\mathrm{K}_{\mathrm{ads}}$ is related to the standard free energy of adsorption, $\Delta G_{a d s}^{\circ}$, by the following equation:

$$
K_{\mathrm{ads}}=\left(\frac{1}{55.5}\right) \exp \left(\frac{-\Delta G^{\circ}{ }_{\mathrm{eds}}}{R T^{\circ}}\right)
$$

where $\mathrm{R}$ is the gas constant, $\mathrm{T}$ is the absolute temperature of the experiment, and the constant value of 55.5 is the concentration of water in the solution in $\mathrm{mol} \mathrm{L}^{-1}$. The $\Delta \mathrm{G}_{\text {ads }}^{\mathbf{b}}$ was calculated as $-43.13 \mathrm{KJ} \mathrm{mol}^{-1}$. The negative value of $\Delta \mathrm{G}^{\mathbf{o}}$ ads indicates the spontaneity of the adsorption process and the stability of the adsorbed layer on the carbon steel surface.

It is well known that the values of $\Delta \mathrm{G}_{\text {ads }}^{\mathrm{o}}$ of the order of $-20 \mathrm{KJ} \mathrm{mol}^{-1}$ or lower indicate a physisorption; those of the order of $-40 \mathrm{~kJ} \mathrm{~mol}^{-1}$ or higher involve a charge sharing or transfer from the inhibitor molecules to the metal surface, to form a coordinate type of bond (chemisorption) [53-54]. On the other hand, the adsorption phenomenon of an organic molecule is not just considered as a purely physical or chemical adsorption phenomenon [55, 56]. A wide spectrum of conditions, from the dominance of chemisorption to electrostatic effects, arises from other adsorptions experimental data [57]. The value of $-43.13 \mathrm{~kJ} \mathrm{~mol}^{-1}$ may suggest chemisorption mode.

\section{Computational studies}

Computational methods have a strong impact towards the design and development of organic corrosion inhibitors.

Nowadays, density function theory (DFT) has been used to analyze the characteristics of the inhibitor/surface mechanism, and to describe the structural nature of the inhibitor on the corrosion process. Furthermore, DFT is considered to be a very useful technique to probe the inhibitor/surface interaction, as well as to analyze the experimental data [58]. Thus, in our present investigation, DFT method was employed to give some insight into the inhibition action of ACMPT molecule on the carbon steel surface. Quantum chemical parameters, such as $\mathrm{E}_{\text {Hомо, }} \mathrm{E}_{\mathrm{Lumo}}$, energy gap, $\Delta \mathrm{E}\left(\mathrm{E}_{\mathrm{LUMO}}-\mathrm{E}_{\mathrm{HOMO}}\right)$ and dipole moment $(\mu)$, were obtained, for the neutral molecule to predict their activity towards the metal surface. These quantum chemical parameters were generated after geometric optimization with respect to all nuclear coordinates.

Fig. 12 shows the optimized geometry of ACMPT: the HOMO optimized structure and frontier orbital distribution, and the LUMO density distribution. Frontier orbital density distribution is useful in predicting adsorption centers of the ACMPT molecule responsible for the interaction with metal surface atoms. As it can be seen from this figure, HOMO is distributed over the entire molecule, but the LUMO density is mainly localized on the dimethoxyphenyl group. The presence of these adsorption centers can cause a flat orientation of ACMPT molecules on the steel surface; thus, a high degree of surface coverage and inhibition efficiency is expected for ACMPT, from the theoretical point of view. These results suggest that $\mathrm{O}$ and $\mathrm{S}$ atoms and two $\mathrm{N}$ atoms are probably the most favorable reactive sites for the adsorption of ACMPT onto the metal surface. 

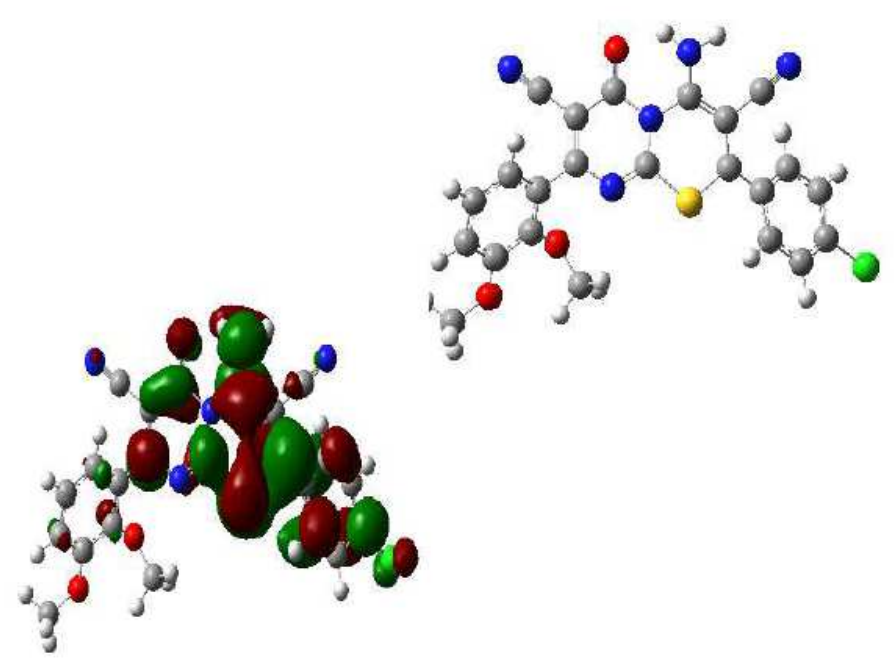

Figure 12. Optimized structures and frontier molecular orbital (FMO) density distribution of ACMPT: HOMO (left) and LUMO (right).

The calculated molecular parameters are listed in Table 8.

Table 8. Quantum chemical parameters for ACMPT calculated by DFT.

\begin{tabular}{lllclll}
\hline $\mathbf{E}_{\text {номо }}(\mathbf{e V})$ & $\mathbf{E}_{\mathbf{L u m o}}(\mathbf{e V})$ & $\Delta \mathbf{E}_{\text {gap }}(\mathbf{e V})$ & $\boldsymbol{\mu}(\mathbf{D e b y e})$ & $\mathbf{I}(\mathbf{e V})$ & $\mathbf{A}(\mathbf{e V})$ & $\Delta \mathbf{N}$ \\
\hline-4.9593 & -2.8882 & 2.0711 & 6.6028 & 4.9593 & 2.8882 & 1.4853 \\
\hline
\end{tabular}

Eномо is often associated with the electron-donating ability of a molecule, and its high value $(-4.9593)$ is likely to indicate a tendency to donate electrons to

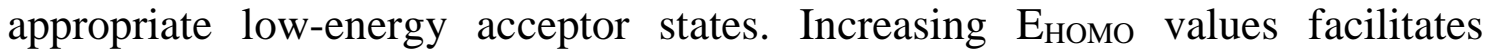
adsorption (and therefore inhibition), by influencing the transport process through the adsorbed layer. E EUMO indicates the ability of the molecule to accept electrons; hence, these are the acceptor states. The lower the value $(-2.8882)$ of

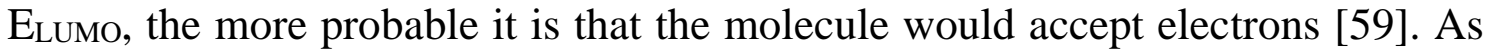
for the values of $\Delta \mathrm{E}$ ( $\left.\mathrm{E}_{\mathrm{LUMO}}-\mathrm{E}_{\mathrm{HOMO}}\right)$, lower values (2.0711) of the energy difference, $\Delta \mathrm{E}$, will cause a higher inhibition efficiency, because the energy to release an electron from the last occupied orbital will be low [60]. For the dipole moment $(\mu)$, a higher value (6.6028) will favor a strong interaction of the inhibitor molecules with the metal surface.

In addition, the number of transferred electrons $(\Delta N)$ was also calculated based on the quantum chemical method [61]:

$$
\Delta N=\frac{\chi_{F e}-\chi_{i n h}}{2\left(\eta_{F e}+\eta_{i n h}\right)}
$$

where $\chi_{\mathrm{Fe}}$ and $\chi_{\text {inh }}$ denote, respectively, the absolute electronegativity of iron and the inhibitor molecule; and $\eta_{\mathrm{Fe}}$ and $\eta_{\text {inh }}$ denote, respectively, the absolute hardness of iron and the inhibitor molecule. These quantities are related to the electron affinity (A) and ionization potential (I).

Absolute electro negativity, $(\chi)$, and absolute hardness, $(\eta)$, of the inhibitor molecules are given by [62]: 


$$
\chi=\frac{I E+E A}{2} \quad \eta=\frac{I E-E A}{2}
$$

IE and EA are related [63] to $\mathrm{E}_{\mathrm{HOMO}}$ and $\mathrm{E}_{\mathrm{LUMO}}$, as follows:

$$
\begin{aligned}
& \mathrm{IE}=-\mathrm{E}_{\text {HOMO }} \\
& \mathrm{EA}=-\mathrm{E}_{\text {LUMO }}
\end{aligned}
$$

For an iron atom, a theoretical $\chi$, with the value of $7 \mathrm{eV} \mathrm{mol}{ }^{-1}$, and $\eta$, with the value of $0 \mathrm{eV} \mathrm{mol}{ }^{-1}$, were used [64] to calculate the number of electrons transferred $(\Delta \mathrm{N})$ from the inhibitor to the iron atom. The number of transferred electrons strongly depends on what the actual quantum chemical method has employed for computation. Furthermore, the expression "number of transferred electrons" is equal to the wording "electron-donating ability", which does not imply that the figures of $\Delta \mathrm{N}$ actually indicate the number of electrons leaving the donor and entering the acceptor molecule.

The value of electron-donating ability $(\Delta N)$ was calculated, and it is given in Table 8. If $\Delta \mathrm{N}<3.6$ (electron), the inhibition efficiency increases with an increasing value of $\Delta N$, while it decreases if $\Delta N>3.6$ (electron) [65, 66]. Based on these data, it can be said that ACMPT is the electron donor, and the surface is the acceptor. ACMPT was bound to the mild steel surface, thus forming an inhibition adsorption layer against corrosion, at carbon steel/hydrochloric acid solution interface.

\section{Conclusions}

From the results of this paper, several conclusions could be listed:

- ACMPT was found to be a good inhibitor for carbon steel in $1.0 \mathrm{M} \mathrm{HCl}$. The inhibition efficiency increases with the inhibitor concentration.

- ACMPT acts as a mixed type inhibitor, with predominant cathodic effectiveness.

- The temperature affects the inhibitory efficiency; this is clearly demonstrated by the decrease in the studied inhibitor effect, with the increase in temperature.

- The adsorption of ACMPT at the carbon steel surface has obeyed the Langmuir's adsorption isotherm.

- The inhibition efficiencies obtained from EIS, Tafel polarization and weight loss methods are in reasonable agreement with each other.

- The calculated parameters obtained from the quantum chemical calculations were correlated with experimental results.

\section{References}

1. Saravanamoorthy S, Velmathi S. Prog Org Coat. 2013;76:1527-1535. 
2. Nam DN, Bui VQ, Mathesh M, et al. Corros Sci. 2013;76:257-266.

3. Nam DN, Somers A, Mathesh M, et al. Corros Sci. 80;2014:128-138.

4. Bobina M, Kellenberger A, Millet JP, et al. Corros. Sci. 2013; 69:389-395.

5. Bilgiç S, Yılmaz H. Mater Chem Phys. 2007;79:5.

6. Ekpe JU, Okafor CP, Ebenso EE, et al. Bull Electrochem. 2001;17:135.

7. Odoemelam AS, Eddy ON. J Surf Sci Technol. 2008;24 :65.

8. Noor AE, Al-Moubaraki AH. Int J Electrochem Sci. 2008;3:806-818.

9. Anejjar A, Salghi R, Zarrouk A, et al. Res Chem Intermediat. 2013;41:913925.

10. Awad KM, Metwally SM., Soliman AS, et al. J Ind Eng Chem. 2014;20:796-808.

11. Soliman AS, Metwally SM, Selim SR, et al. J Ind Eng Chem. 2014;20:4311-4320.

12. Awe EF, Idris OS, Abdulwahab M, et al. Cogent Chem. 2015;1.

13. Belayachi $M$, Serrar $H$, Zarrok $H$, et al. Int $J$ Electrochem Sci. 2015;10:3010-3025.

14. Belayachi M, Serrar H, Assyry AE, et al. Int J Electrochem Sci. 2015;10:3038-3053.

15. Larouj M, Elaoufir Y, Serrar H, et al. Pharm Lett. 2014;6:324-334.

16. Larouj M, Belkhaouda M, Lgaz H, et al. Pharm Lett. 2016;8:114-133

17. Zarrok H, Zarrouk A, Hammouti B, et al. Corros. Sci. 2012;64:243-252.

18. Obot BI, Obi-Egbedi ON. Curr Appl Phys. 2011;11:382-392.

19. Ma H, Chen S, Liu Z, et al. J Mol Struct THEOCHEM. 2006:774;19-22.

20. Henríquez-Román HJ, Padilla-Campos L, Páez AM, et al. J Mol Struct THEOCHEM. 2005;757:1-7.

21. Rodríguez-Valdez ML, Martínez-Villafañe A, Glossman-Mitnik D. J Mol Struct THEOCHEM. 2005;713:65-70.

22. Feng Y, Chen S, Guo W, et al. J Electroanal Chem. 2007;602;115-122.

23. Frisch JM, Trucks WG, Schlegel BH, et al. Gaussian 03, Revision E.01, Gaussian, Inc, Wallingford CT; 2004.

24. Dewar SJM, Thiel W. J Am Chem Soc. 1977;99:4899-4907.

25. Pearson GR. Inorg Chem. 1988;27:734-740.

26. Sastri SV, Perumareddi RJ. Corrosion. 1997;53:617-622.

27. Lukovits I, Kálmán E, Zucchi F. Corrosion. 2001;57: 3-8.

28. Fu J, Zang H, Wang Y, et al. Ind Eng Chem Res. 2012;51:6377-6386.

29. Qiang Y, Zhang S, Xu S, et al. J Colloid Interface Sci. 2016;472:52-59.

30. Abd El-Lateef MH, Abbasov MV, Aliyeva IL, et al. Mater Chem Phys. 2013;142:502-512.

31. Abd El-Lateef MH, Abbasov MV, Aliyeva IL, et al. J Korean Chem Soc. 2013;57 (1):25-34.

32. Abd El-Lateef MH. Corros Sci. 2015;92:104-117.

33. Abd El-Lateef MH, Ismael M, Mohamed I. Corros Rev. 2015;33:77-97.

34. Marusic K, Curkovic OH, Takenouti H. Electrochim Acta. 2011;56:74917502.

35. Khaled KF, El-Maghraby A. Arabian J Chem. 2014;7.3:319-326.

36. El Azzouzi M, Aouniti A, Tighadouin S, et al. J Mol Liq. 2016;221:633-643. 
37. Elmsellem H, Aouniti A, Khoutoul M, et al. J Chem Pharm Res. 2014;6:1216.

38. Khaled FK. Electrochimica Acta. 2003;48:2493-2503.

39. Aljourani J, Raeissi K, Golozar AM. Corros Sci. 2009;51:1836-1843.

40. Chaitra KT, Mohana SNK, Tandon CH. J Mol Liq. 2015;211:1026-1038.

41. Niu L, Zhang H, Wei F, et al. Appl Surf Sci. 2005;252:1634 1642.

42. Umoren AS, Ebenso E. Mater Chem Phys. 2007;106:387-393.

43. Feng Y, Siow SK, Teo KW, et al. Corros Sci. 1999;41:829-852.

44. Wenner M, Branan N, Stern V, et al. Sci Am Mind. 2008;19:82-83.

45. Li P, Lin YJ, Tan LK, et al. Electrochimica Acta. 1997;42:605-615.

46. Mu NG, Li X, Li F. Mater Chem Phys. 2004;86:59-68.

47. Lebrini M, Robert F, Roos C. Int J Electrochem Sci. 2010;5:1698.

48. Moretti G, Quartarone G, Tassan A, et al. Electrochimica Acta. 1996;41:1971-1980.

49. Growcock BF, Lopp VR. Corros Sci.1988;28:397-410.

50. Zarrouk A, El Ouali I, Bouachrine M, et al. Res Chem Intermediat. 2012;39:1125-1133.

51. Ali AS, Saeed MT, Rahman US. Corros Sci. 2003;45:253-266.

52. Migahed AM. Mater Chem Phys. 2005;93:48-53.

53. Ahamad I, Prasad R, Quraishi AM. Corros Sci. 2010;52:933-942.

54. Noor AE, Al-Moubaraki HA. Mater Chem Phys. 2008;110:145-154.

55. Özcan M, Solmaz R, Kardaş G, et al. Colloids Surf A. Physicochem Eng Asp. 2008;325:57-63.

56. Solmaz R. Corros Sci. 2010;52:3321-3330.

57. Döner A, Solmaz R, Özcan M, et al. Corros Sci. 2011;53:2902-2913.

58. Moretti G, Guidi F, Grion G. Corros Sci. 2004;46:387-403.

59. Guadalupe JH, García-Ochoa E, Maldonado-Rivas JP, et al. J Electroanal Chem. 2011;655;164-172.

60. Gece G. Corros Sci. 2008;50:2981-2992.

61. Issa MR, Awad KM, Atlam MF. Appl Surf Sci. 2008;255:2433-2441.

62. Sastri SV, Perumareddi RJ. Corrosion. 1997;53:617-622.

63. Pearson GR. Inorg Chem. 1988;27:734-740.

64. Bentiss F, Traisnel M, Lagrenee M. Corros Sci. 2000;42:127-146.

65. Bentiss F, Traisnel M, Lagrenee M. J Appl Electrochem. 2001;31:41-48.

66. Lukovits I, Kálmán E, Zucchi F. Corrosion. 2001;57:3-8. 